substantial contribution in employment and sporting rates to the Highland economy which the Red Deer make, it will surely be wrong if Great Britain is the only country in Europe and North America without a close season for the protection of its native Red Deer.

\title{
THE GREAT INDIAN ONE-HORNED RHINOCEROS
}

\author{
By E. P. GEe
}

The Great Indian One-horned Rhinoceros, probably India's rarest and most interesting animal, occupies a unique position in the world to-day. Listed by the survival service of the International Office for the Protection of Nature as one of the vanishing species which requires all possible steps to be taken for its protection, it has the eyes of scientists, naturalists and others in all parts of the world focussed on it and its habitat.

Formerly spread over most of the northern part of the Indian sub-continent, it is now confined to a few low-lying and thickly reeded tracts of Nepal and North-East India. It is estimated that there are some fifty head of rhino in Nepal, and it is to be hoped that the Government of that country can be persuaded to protect it fully--even from being shot by privileged persons.

Some 300 rhino are believed to exist in India : 2 in Bihar State (in Champaran Iistrict, probably wanderers from Nepal), 58 in Bengal, and 240 in Assam. The 58 in Bengal are accounted for as follows: 3 in the Garumara Sanctuary of Jalpaiguri District, 30 in the Jaldapara Sanctuary of Buxa District, and 25 in Cooch Behar.

The main stronghold for India's rhino is the State of Assam. Her 240 rhino are distributed thus : 45 in the North Kamrup (Manas) Wild Life Sanctuary, 150 in the Kaziranga Wild Life Sanctuary, 5 in the Sona Rupa Reserve, 10 in the Orang Reserve, 20 in the Laokhowa Reserve, and 10 clsewhere. All the figures given are approximate, based on conservative estimates made by the most experienced persons concerned with the preservation of this rare animal.

\section{Census not Possible}

A proper census of rhino is not humanly possible. Even in Kaziranga attempts to hold a census from the air have failed, owing to the extensive patches of 15-feet-tall elephant grass 
which cover most of the sanctuary. Only a very small percentage of this elephant grass can be burnt off each year.

It is within the realm of possibility that there may be more than 150 rhino in the 165 square mile area of Kaziranga, say even up to 250 or 300 head ; but wishful thinking and optimism are dangerous pitfalls to be guarded against, especially when one considers the slender thread on which the survival of these valuable creatures is suspended. Disease contracted from domestic cattle grazing in the vicinity of sanctuaries in Assam accounts for many rhino deaths. For instance, in 1944 some twenty-two horns were collected in Kaziranga from rhino which had dicd from some disease; and again in 1947 the carcases of fourteen rhino were found in Kaziranga after an unreported outbreak of anthrax among the cattle of a village nearby. Many more may have died without their remains having been found.

Only about two rhino each year seem to be lost in Kaziranga through poaching, and it is possible that the market for rhino horn has been affected by conditions in China during the last decade. Poachers exist in large numbers, and there is much illegal shooting both on the fringes of the sanctuary and all round it, often in the name of crop protection. The handsome Indian Swamp Deer has almost disappeared, and even Hog Deer are becoming scarce. Gaur (Indian "bison ") have entirely vanished both from the sanctuary and from the neighbouring Mikir Hills.

It is my personal view that the numbers of rhino rose from the much depleted stock of a dozen or so in 1908 to about 400 in 1940, but have now become reduced to some 250. For the sake of being on the safe side, however, I prefer to abide by the more conservative estimate of 150 .

An examination of the entries of animals seen, as recorded in the visitors' book of Kaziranga, reveals that from 1944 onwards fewer rhino were observed than in the years 1937 (when the sanctuary was first opened to visitors) to 1943. Again, the figures of rhino seen in the years following 1947 are still fewer. This almost certainly has a direct relation to the outbreaks of disease in the sanctuary.

\section{Encouraging Signs}

It is pleasing, however, to note that the number of rhino seen so far in 1951 in Kaziranga is greater than in the previous year ; and it appears that if we can solve the problem of trespass by villagers with their cattle, and if we can eliminate cattle 
disease in the neighbourhood of the sanctuary by means of compulsory inoculations and the like, the safety and ultimate survival of rhino can be ensured. In this respect it is most gratifying to be able to report that vigorous steps actually have now been taken to eradicate rinderpest from the area of Kaziranga. During the month of December, 1951, an enterprising team from the Veterinary College of Gauhati were engaged in inoculating for a five-year immunity all the domestic cattle and buffaloes belonging to the nearby graziers and villagers. The team, consisting of the Vice-Principal of the College, four Professors, two Lecturers, and twenty-four Students, were divided into four parties. They worked energetically, often at night, and in a period of three weeks or so, inoculated a total of some 50,000 animals-a very praiseworthy effort on the part of the College personnel concerned.

A heartening feature on a visit to the sanctuary is the sight of rhino calves. On three visits made early in November, 1951, I saw a total of nineteen rhino, of which three were calves. One of these was a half-grown calf, but the other two were nerdy born. I estimated that the height of these two very young calves was not much more than 2 feet and $2 \mathrm{ft}$. 3 in. respectively, and I therefore put their ages at about two weeks and four weeks.

That rhino calves are usually born in October is also supported by the fact that in the case of a rhino calf of the same species being born in captivity in 1925 at the Calcutta Zoological Gardens, the birth took place on 9th October. This birth was reported to be "unfortunately somewhat premature", and the $1 \mathrm{ft} .11 \mathrm{in.} \mathrm{high} \mathrm{baby} \mathrm{only} \mathrm{survived} \mathrm{a} \mathrm{few} \mathrm{hours.}$

The mating of this pair of rhino in the Calcutta Zoo took place in the second half of March, 1924, which would make the period of gestation about eighteen and a half months. Rhino in Kaziranga have been observed in the act of mating on only three occasions since the sanctuary was opened in 1937: on 17th April, 1938, on 24th February, 1940, and on 25th April, 1944. Careful observation is needed to build up our knowledge of the life history of this species of rhino.

\section{Kaziranga Wild Life Sanctuary}

Increased interest has been taken in the Great Indian Onehorned Rhinoceros and its sanctuaries during the last few years. In keeping with the times, the words "Game Sanctuary" has been suitably changed to "Wild Life Sanctuary". In the case of Kaziranga Wild Life Sanctuary, which is the show- 


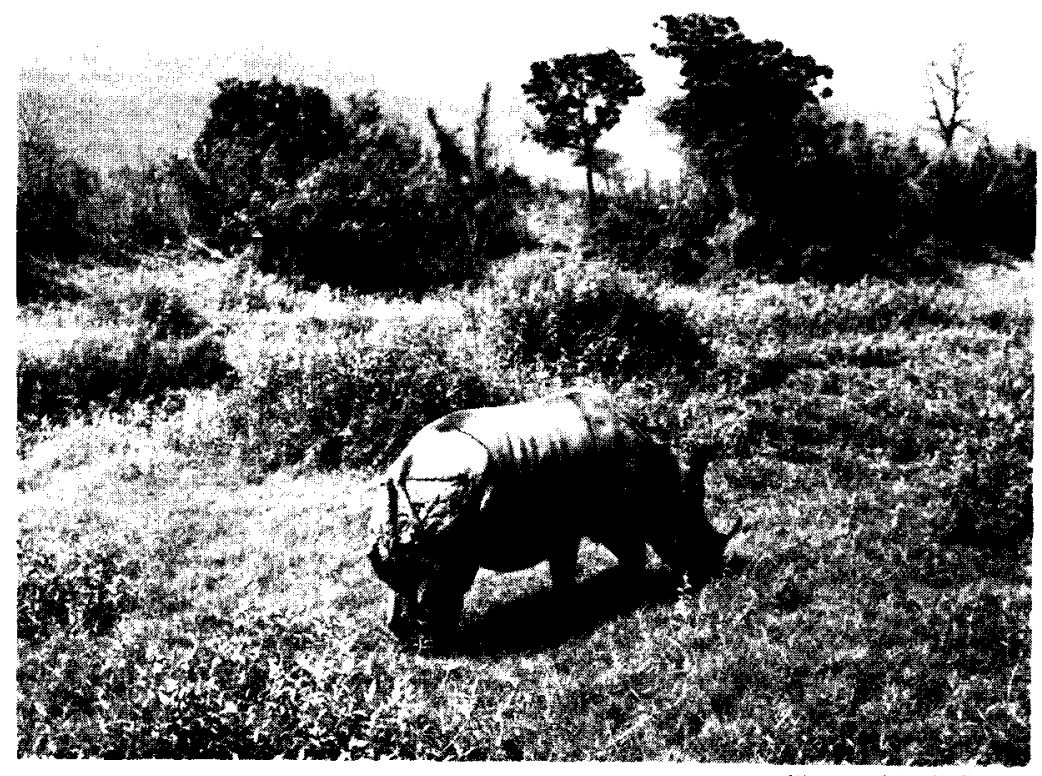

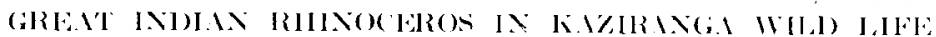

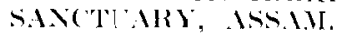

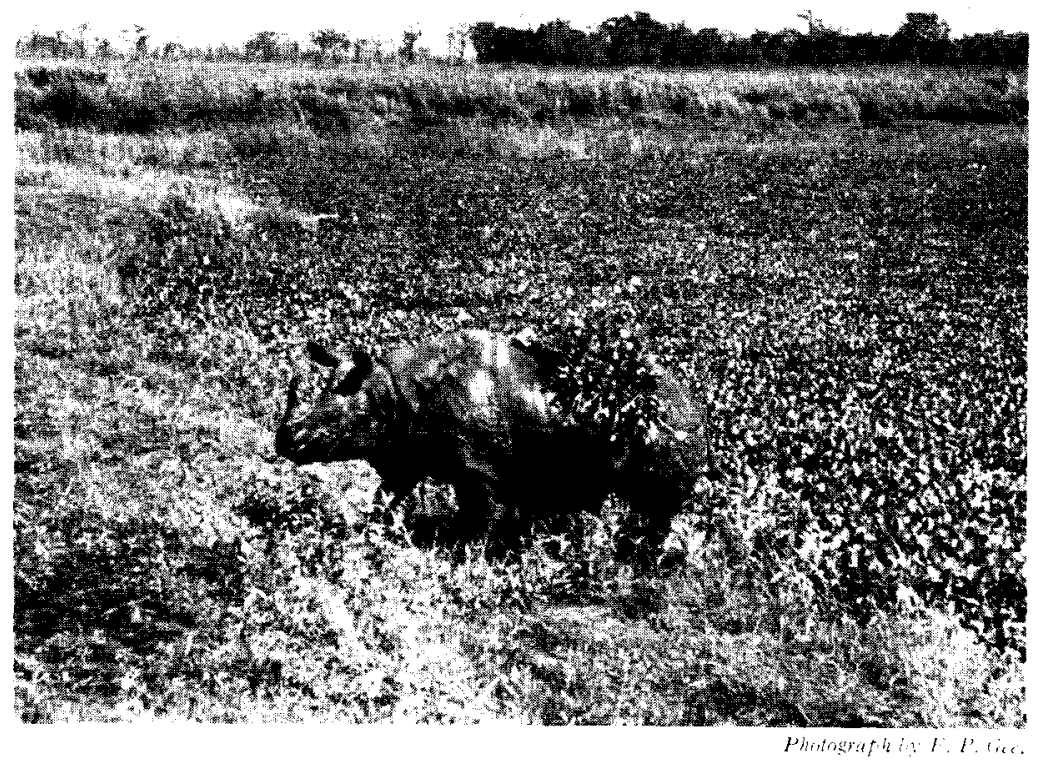

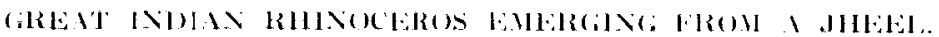


place for rhino in Assam, and therefore in India, a fair-weather access road from the Trunk Road to the boundary of the sanctuary has been constructed. Visitors can now motor in the dry weather right up to the edge of the sanctuary, and a considerable saving of time is effected.

The Forest Bungalow at Baguri has been reconditioned and improved; and now actually boasts of electric light (when it works) and sanitation, as well as a complete outfit of crockery, cutlery and mattresses, etc. I understand that the Forest Department hope to arrange for a cook during the season of the cold weather, if a satisfactory flow of visitors can be assured.

As for inspection elephants, the two old stagers, Akbar and Sherkhan, have been reinforecd by Mohan and two very likeable youngsters, Shivasingha and Mohanprosad. Shivasingha is a tusker and should in time be a worthy successor to the aged but staunch Akbar.

\section{Tire Future:}

It is gratifying to note that there is a gradual, though slow and long overdue, awakening among the public of Assam to the value of the State's wild life and to the need of its preservation. A Wild Life Committee has recently been formed, whose function will probably be mainly "advisory". But as it includes many prominent persons, both official and non-official, and as it is under the chairmanship of H.E. The Governor, and under the vice-chairmanship of the Honourable Chief Minister and the Honourable Ministers of Forests and Food and Agriculture, it is hoped that its advice will carry considerable weight.

In addition to steps for the preservation of wild life in general, one of the primary objectives of this new Committee is the creation of two National Parks in Assam : Kaziranga and North Kamrup (Manas). As these are the two main strongholds in the world of the Great Indian One-horned Rhinoceros, there is now much more hope for the ultimate survival of this interesting creature for posterity. 